\title{
Population Heterogeneity and the Sociogenesis of Homicide ${ }^{*}$
}

\author{
HE N R Y B . H A N S M A N N, University of Pennsylvania
}

J OH N M. Q U I G L Y, University of California, Berkeley

\begin{abstract}
It has frequently been suggested that a high degree of social heterogeneity is conducive to a high rate of crime. This paper explores that hypothesis by providing an explicit statistical test of the relationship between a society's homicide rate and various measures of the ethnic, linguistic, religious, and economic heterogeneity of that society's population, using nationstates as units of observation. The results lend support to the theory that the interaction within a society of heterogeneous cultural groups tends to increase the rate of homicide. The empirical analysis controls for the effect on homicide rates of the age structure of the population, per capita GNP, urbanization, and population density; the results suggest that the first two of these factors are also important in explaining variations in homicide rates.
\end{abstract}

Rates of crime, particularly rates of violent crime, vary enormously among nations. In the popular mind such varying rates of crime are commonly attributed to relative differences in the heterogeneity of population. ${ }^{1}$ Informal arguments to this effect have also been advanced by several researchers. For example, in comparing Japan's low crime rate to that of the United States, Bayley suggested that the substantial cultural homogeneity of the Japanese population has helped to establish a moral consensus in Japanese society, which in turn has enhanced the effectiveness of both formal and informal authority. Likewise Porterfield (b), commenting on crime in Finland, emphasized the considerable ethnic diversity of the nation's population. He concluded that, because of the stress that it creates, "this heterogeneity may well account for the fact that the nation as a whole has a higher than average rate of both suicide and homicide" (173).

\footnotetext{
*Prepared under Grant \#75-NI-99-0127 from the National Institute of Law Enforcement and Criminal Justice, Law Enforcement Assistance Administration, Department of Justice, and by a grant from the Sloan Foundation. This paper benefited from the comments of David $\mathrm{H}$. Bayley, Wendell Bell, James Q. Wilson, Marvin E. Wolfgang, and the members of the Berkeley Demography Workshop. Research assistance was provided by James Trask and Michael Woodford. The usual caveats apply.
}

- 1982 The University of North Carolina Press. 0037-7732/82/010206-24\$01.90 
Several statistical analyses using United States data claim to establish a relationship between crime rates and the heterogeneity of local populations. For example, Porterfield (a) computed a correlation of .53 between statewide average data on serious crimes and an index of homogeneity for each state (defined as the sum of the percent deviations from the national average in the proportion of individuals in the state who (a) had changed their county of residence within the previous five years and (b) were "others than native whites"). He concluded that this correlation supports the hypothesis that heterogeneity is a measure of "social disorganization and cultural differentiation," and that these factors in turn influence the crime rate.

In a similar study of $\mathbf{1 1 2}$ metropolitan areas in the United States, Angell (a) found a correlation coefficient of .35 between a composite crime index and an index of the "heterogeneity of the population," constructed by adding the fraction of foreign-born whites to twice the fraction of nonwhites. Angell took the crime rate to be an index of the moral integration of the city, and interpreted his results as support for the hypothesis that greater heterogeneity has a deleterious effect on moral integration. (See also Angell, b.)

Both the Porterfield and Angell studies are subject to the criticism, among other objections, that their heterogeneity indices are in considerable part simply measures of the size of the nonwhite population. Consequently Lander's analysis of the incidence of juvenile delinquency among census tracts in Baltimore has special interest. Lander found that the rate of delinquency for both whites and blacks increased as the percentage of blacks in the area rose from 0 to about 50 percent, and then decreased as the percentage of blacks rose from 50 to 100 percent. Lander concluded that "[a]reas of maximum racial heterogeneity are characterized by the largest extent of social instability and anomie" (83). Subsequently, however, Bordua was unable to replicate this result using data from Detroit.

Cross-national data have been employed in one study, by McDonald, which includes an investigation of the relationship between population heterogeneity and criminal activity across a sample of 40 nationstates. Based on separate trivariate regressions, each relating homicide rates to one or another single measure of racial, religious, or linguistic heterogeneity, McDonald inferred that: "Murder rates were higher in societies that were heterogeneous with respect to language, though neither religious nor racial heterogeneity had any effect" (173). In similar regressions using indices for crime other than homicide, none of the heterogeneity measures showed up as significant. McDonald argued that his results negate "social problems explanations" of crime: "Indicators of heterogeneity in the population, thought both to cause problems and to make their solution more cumbersome, completely failed to have the predicted effect in the main data set" (175). In McDonald's study, however, hetero- 
geneity is represented merely by a dummy variable with a value of one if an arbitrary fraction of the population ( 80 percent for religion, 85 percent for language, 90 percent for race) shared a common religion, language, or racial identity. Moreover, the study does not explore the joint influence of different heterogeneity measures, however defined, upon criminal activity -an omission that, as suggested below, may make McDonald's results seriously misleading.

None of these authors gives a precise account of the social mechanisms that might link population heterogeneity to criminal activity. Several theories are, however, suggested by their observations or by the various comments that they offer concerning causal relationships.

The most straightforward theory is simply that people are inclined to feel antagonistic to, and to act abusively toward, others who are physiologically or culturally different from themselves. Blau has in fact employed such logic as the basis for a theoretical prediction that heterogeneity will breed interpersonal conflict, including crime. Such a theory, however, is inconsistent with the fact that the great bulk of crime, especially violent crime, is evidently intra-group, even in heterogeneous societies. For example, Wolfgang's study (b) of homicide in Philadelphia showed that 94 percent of all homicides were intra-racial, and Garfinkel's study of North Carolina homicides found that 90 percent were intra-racial. It appears, then, that any social or psychological theory linking heterogeneity to crime must demonstrate a mechanism whereby an increase in the number of groups in a society leads to a higher crime rate within each group.

One such mechanism might be inferred from psychological theories of displaced aggression (Brown; Buss; Dollard et al.; Fenigstein and Buss; Holmes; Konecni and Doob). While individuals may be inclined to feel aggressive toward others who are culturally or physiologically different, that aggression may in fact often be taken out on members of the individual's own group, who tend to be more accessible. Further, such behavior might be aggravated by a tendency for socioeconomic classes to appear particularly rigid in the presence of obvious cultural or physiological differences among social groups. Members of the lowest-status groups in society might feel that their opportunities for social mobility are especially restricted when upper-class persons are obviously and identifiably different from themselves, and the resulting frustration could lead to an unusually high incidence of criminal behavior.

A rather different theory is that group norms and sanctions tend to break down in the presence of conflicting cultures. Thus, as Bayley notes in his observations on Japan, collective mechanisms for maintaining order - such as criminal statutes, the courts, and the police-may receive greater respect and cooperation from the citizenry at large if there is a strong consensus as to the means and ends of law enforcement and if all citizens identify strongly with the particular individuals who are charged with en- 
forcing the law. Similarly, and perhaps more importantly, it seems plausible that the informal mechanisms for maintaining order within a given cultural group could become weakened through contact with other groups. The moral authority of one's own culture, and of the types of sanctions that support it, may lose some of their strength when one is continually exposed to other cultures. Likewise, an individual's respect for himself and for other members of his group may be diminished by contact with those who are different-and who may even be perceived as superior-culturally, racially, or economically. The result could be a weakening of group norms as a whole-including those, such as disapproval of violence and theft, that are largely shared by all of the groups involved. ${ }^{2}$

Reasoning of this sort is suggested, explicitly or implicitly, by some of those who see culture conflict as an important source of crime (McDonald; Sellin). ${ }^{3}$ Such a tendency toward normlessness in heterogeneous environments is also invoked more or less clearly by Lander (89) and, as he notes, it is at least arguably consistent with Durkheim's theory of anomie $^{4}(89)$.

Most discussions of the relationship between population heterogeneity and crime seem premised on the implicit assumption that heterogeneity is a unitary phenomenon. In fact, however, there are many different dimensions in which a society can be heterogeneous, and it is not obvious that each of these types of heterogeneity should bear the same relationship to levels of criminal activity. Racial, religious, and linguistic heterogeneity might, for example, have quite different effects on crime rates. Indeed, it is plausible a priori that at least some forms of population heterogeneity might have a negative effect on criminal activity. Linguistic heterogeneity might, for example, tend to reduce contact between population subgroups that are heterogeneous in other dimensions (such as race or religion), and consequently mitigate tensions that would otherwise arise from the interaction of those subgroups. (For further discussion, see below.) ${ }^{5}$

Somewhat surprisingly -in light of the considerable theorizing and the suggestive though limited empirical observations that have appearedthere is nowhere in the literature a detailed rigorous statistical test of the relationship between population heterogeneity and criminal activity within or between societies. The remainder of this paper provides such a test and an interpretation of the results.

\section{The Statistical Model}

A general hypothesis about the effect of population heterogeneity (a vector $H$ ) on criminal activity $(C)$ may be described as 
$C=f(H ; 0)$

where 0 refers to other relevant factors, presumably held constant.

Clearly, a persuasive statistical test of the general hypothesis requires that other factors be held constant in some convincing way. One strategy would be to rely on repeated observations on a single society, fixing on the dynamic, albeit short run, relationship between heterogeneity and criminal activity. Another strategy would rely on cross-sectional observations from different societies, and thus would focus attention on the static, but long run, relationship between criminal activity and heterogeneity. The former strategy would exploit data containing less variation and would require careful attention to exogenous, time varying phenomena (see, e.g., Wolpin). The latter strategy, based on data containing more variation, would be more prone to measurement error; for this reason alone we would expect the proportion of explained variation to be lower when based on cross-sectional data.

The analysis reported below is based on data for some 58 nationstates. ${ }^{6}$ At present it does not appear that sufficient time series information exists, even for developed nations, to support a meaningful dynamic analysis.

A test of the general hypothesis requires specification and measurement of criminal activity, heterogeneity, and other factors, as well as the functional form $(f[. ;])$ of the relationship.

\section{CRIMINAL ACTIVITY}

This analysis deals exclusively with the rate of homicide, or purposely inflicted deaths, as a measure of criminal activity $(\mathrm{C})$. The principal reasons for this are: (1) among all crimes, homicide appears to vary least in definition from one society to the next (Ferdinand; Hindelang; Wolfgang, a); (2) homicide statistics are probably more reliable than other crime statistics for most societies, owing to the serious nature of the crime and the likelihood that it will come to the attention of the authorities (Clinard and Abbott; Mulvihill and Tumin); (3) data on homicide are available for a wider range of societies than are data on other crimes; and (4) homicide seems less likely to arise directly from rational profit-maximizing motives than crimes against property (Becker).

Average annual homicide rates were obtained for a sample of 58 nations. The figures include not just criminal homicides, but all deaths purposely inflicted by other persons and by the state, except for deaths related to acts of warfare. Such a broad measure has a major advantage in comparing incidence across societies: it is independent of differences among societies in the definition of excusable homicide. This also means, however, that these homicide rates cannot be interpreted as a precise 
measure of those purposely inflicted deaths actually considered criminal by the societies involved.

Although the accuracy, and in some cases the definition, of these homicide rates undoubtedly varies from one nation to the next, for the limited purposes of this analysis we do not require that homicide rates be reported without error; it is sufficient simply that any errors in the homicide rates be uncorrelated with the heterogeneity measures and other variables discussed below. It is difficult to establish whether this condition is met by this (or any other) body of data. Errors in reporting homicide rates may be truly random. Under these circumstances the variance of the stochastic error term would be needlessly high, but neither its expected value nor its variance would vary with other factors. Alternatively, it may well be that the accuracy of reported homicide rates varies positively with levels of modernization and development, and that the level of consistency of definition with the United Nations definition of homicide (which the data purportedly follow in most cases) also varies positively with these factors. Under these latter circumstances, the variance of the stochastic error term, but not its expected value, would vary inversely with measures of economic development or modernization.

Under either the former or latter conditions, errors in homicide rates would be uncorrelated with the other variables in the model, and coefficient estimates would be unbiased, though inefficient. Thus any formal test of the statistical significance of heterogeneity upon crime would be more conservative-formal tests would be biased towards accepting the null hypothesis of no relation between homicide rates and heterogeneity (Hanushek and Jackson). It is certainly possible to imagine situations where the error terms would be correlated with other factors included in the model and where, as a result, coefficient estimates would be biased and inconsistent. We have no direct evidence on the issue. In any case, while we suspect that the accuracy and consistency of measurement varies across societies according to their level of development, we have no a priori reason to suspect that the expected values of the errors is correlated with the explanatory variables discussed below.

\section{HETEROGENEITY}

We have constructed four measures of the economic, cultural, and social heterogeneity of societies. These include measures of the heterogeneity of income, language, ethnicity, and religion within each country.

Heterogeneity in income (a cardinal scale with a well-defined zero point, in contrast to language, religion, and ethnicity) was measured by the Gini coefficient. This index has an extreme value of zero if incomes are perfectly equal for all individuals; larger values (bounded by one) signify greater inequality or heterogeneity in income. 
Measures of the heterogeneity of language, ethnicity, and religion for each country were constructed using entropy indices (see Theil). The entropy index for religion, for example, was computed from the proportion of the population $\left(p_{i}\right)$ belonging to each major religion $i=1,2, \ldots, N$. The entropy measure of religious heterogeneity, $H_{R}$, is

$H_{R}=\sum_{i=1}^{N} p_{i} \log p_{i} 1$.

If everyone in the society is a member of the same religion $\left(p_{1}=1\right)$, then the index takes the value zero. Higher values correspond to a more heterogeneous population. For a society with adherents to $M$ religions, the index is at a maximum when the population is equally divided among those religions. Likewise, the index is higher for a population equally divided among $M$ religions than it is for a population equally divided among $M-1$ religions. (See Allison for a detailed discussion.)

Neither the Gini index nor the entropy index is a unique measure of heterogeneity. However, the Gini coefficient has the desirable properties of symmetry and scale invariance in measuring inequality along a cardinal scale such as income. Moreover, for discrete categories such as religion, ethnicity, or language, the entropy index is the only measure of heterogeneity with the properties of continuity, symmetry, and additivity (Allison; Theil).?

Entropy measures of the religious, ethnic, and linguistic heterogeneity of each country were computed by classifying the population of each country in terms of eight major religions, more than a hundred principal languages spoken, and more than a hundred possible ethnic backgrounds.

Strictly interpreted, the validity of the entropy measures used here depends on the prior classification of populations into categories that are mutually exclusive and exhaustive, and that are also equally distant from each other. The latter criterion would be met for the linguistic categories, for example, if speakers of one language could never understand speakers of another. Breaking down all languages further into dialects, on the other hand, would cause a society divided equally among speakers of two dialects of the same language to rank the same on the heterogeneity index as a society divided equally among speakers of one of those dialects and speakers of an entirely different language.

In defining categories for the entropy indices we have made no effort to second-guess the sources of our linguistic and ethnic data (which come largely from the cross-national data files assembled by Taylor and Hudson), but rather have taken the data as we found them. Whatever the potential defects of the categorizations that underlie the heterogeneity indices, all categories have been applied consistently from one country to the next. That is, the indices are based on objective measures of ethnicity, 
language, and religion that are independent of national context. ${ }^{8}$ Otherwise the indices would be measures not just of objective heterogeneity, but also of those factors that cause the population of one nation to create, or perhaps just to perceive, important distinctions between population subgroups where another nation does not. In the latter case, a positive correlation between (apparent) diversity and crime could simply reflect a high correlation between a nation's crime rate and the sensitivity of its citizens to various genetic and cultural differences found among themselves.

\section{OTHER VARIABLES}

We also obtained measures of several other social, economic, and demographic factors, primarily to serve as controls on the tests of the heterogeneity hypothesis, but also because their relationship to homicide rates is of interest in its own right. These variables include population density, a measure of urbanization (the percentage of the population living in cities larger than 100,000), gross national product per capita, and the percentage of the population between 15 and 25 years of age.

It was possible to obtain all these data for a sample of 58 nations, with the exception of the Gini coefficient measuring income inequality, which was available for a subset of only 40 nations. Table 1 provides summary information on the variables collected for the 40 nation sample and for the 58 nation sample. The annual homicide rate for these samples is about 5 per 100,000 , with a standard deviation of 6 . There is considerable variation in the measures of religious, ethnic, and linguistic heterogeneity; heterogeneity of income varies somewhat less. It should be noted that the ethnic and religious entropy measures are highly correlated, at about .8, in each sample. This, of course, does not affect the expected value of coefficient estimates, but, as noted below, results require a judicious interpretation.

\section{Results}

Table 2 presents ordinary least-squares regression estimates of equation (1) in six variants. Each variant includes the estimated coefficients of the measures of religious, ethnic, and linguistic heterogeneity. The (unstandardized) coefficients are interpreted as the effect of a one unit change in each variable on the homicide rate, holding other variables constant. For the larger sample of 58 nations, three regressions are presented: the first includes only the three measures of heterogeneity; the second includes the variable reflecting the youthful population; the third also includes the measures of population density, urbanization, and per capita income. For 


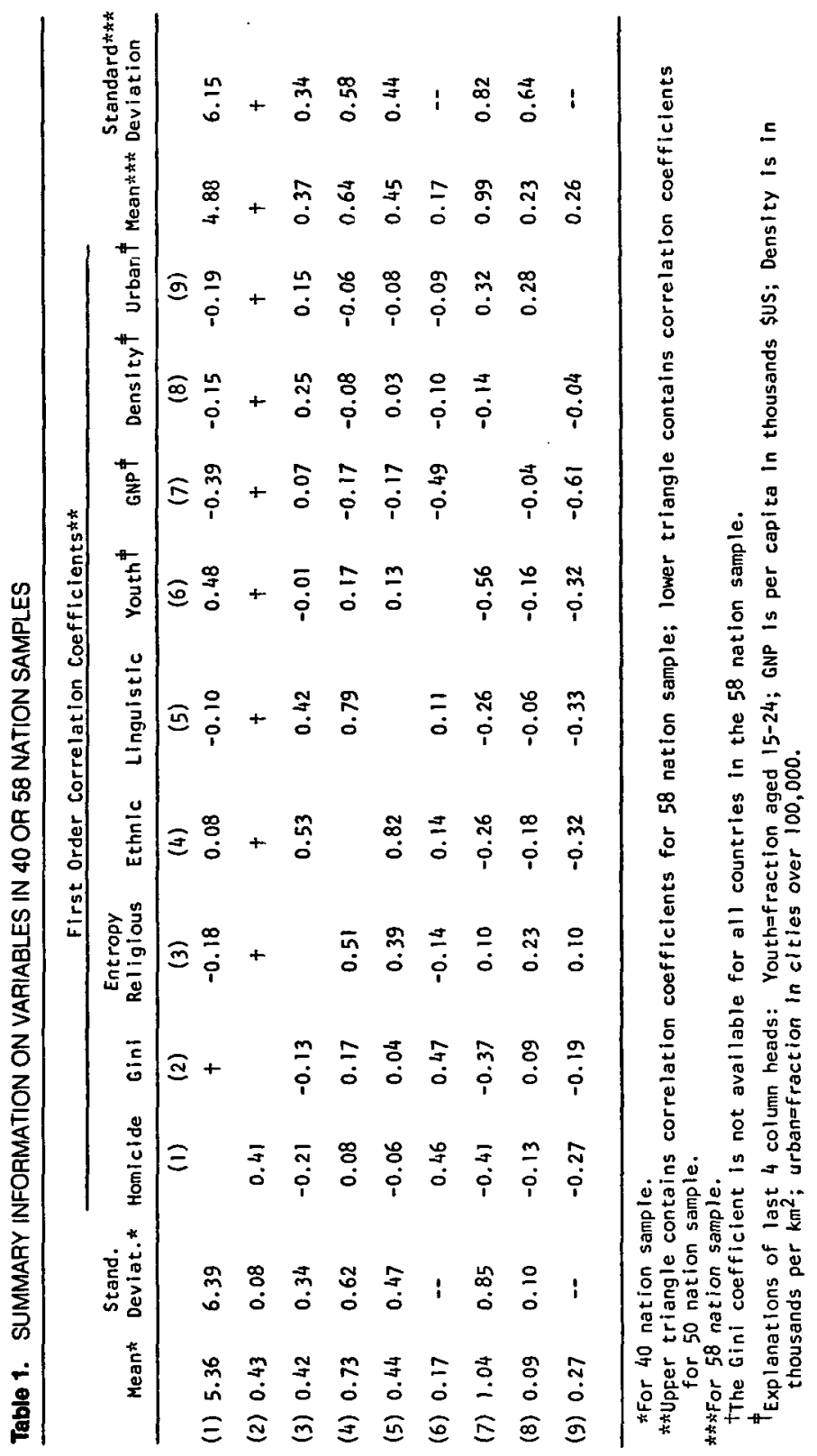


Table 2. ORDINARY LEAST-SQUARES REGRESSION COEFFICIENTS* (DEPENDENT VARIABLE: HOMICIDE RATE PER 100.000)

\begin{tabular}{|c|c|c|c|c|c|c|}
\hline \multirow[b]{2}{*}{ Variant } & \multicolumn{3}{|c|}{58 Countries } & \multicolumn{3}{|c|}{40 Countries } \\
\hline & (1) & (2) & (3) & (4) & (5) & (6) \\
\hline$\frac{\text { Heterogeneity }}{\text { Religion }}$ & $\begin{array}{l}-5.53 \\
(2.1)\end{array}$ & $\begin{array}{l}-4.42 \\
(1.9)\end{array}$ & $\begin{array}{l}-3.51 \\
(1.3)\end{array}$ & $\begin{array}{l}-4.70 \\
(1.4)\end{array}$ & $\begin{array}{l}-3.79 \\
(1.2)\end{array}$ & $\begin{array}{l}-3.37 \\
(0.9)\end{array}$ \\
\hline Ethnicity & $\begin{array}{r}6.14 \\
(2.6)\end{array}$ & $\begin{array}{r}4.95 \\
(2.4)\end{array}$ & $\begin{array}{r}4.61 \\
(2.1)\end{array}$ & $(1.3)$ & $\begin{array}{r}3.79 \\
(1.3)\end{array}$ & $\begin{array}{l}3.49 \\
(1.1)\end{array}$ \\
\hline Language & $\begin{array}{l}-5.85 \\
(2.1)\end{array}$ & $\begin{array}{l}-5.83 \\
(2.3)\end{array}$ & $\begin{array}{l}-6.11 \\
(2.4)\end{array}$ & $\begin{array}{l}-3.85 \\
(1.1)\end{array}$ & $\begin{array}{l}-4.39 \\
(1.3)\end{array}$ & $\begin{array}{l}-4.96 \\
(1.4)\end{array}$ \\
\hline Income & & & & $\begin{array}{l}25.83 \\
(2.1)\end{array}$ & $\begin{array}{l}14.32 \\
(1.1)\end{array}$ & $\begin{array}{l}12.80 \\
(0.9)\end{array}$ \\
\hline$\left.\frac{\text { Other Variables }}{\text { Youth (\& pop. ages }} \quad 15-24\right)$ & & $\begin{array}{r}1.73 \\
(3.9)\end{array}$ & $\begin{array}{r}1.40 \\
(2.7)\end{array}$ & & $\begin{array}{r}1.40 \\
(2.0)\end{array}$ & $\begin{array}{l}1.02 \\
(1.3)\end{array}$ \\
\hline $\begin{array}{l}\text { GNP per capita (thousands } \\
\text { of U.S. dollars) }\end{array}$ & & & -1.34 & & & $\begin{array}{l}-0.98 \\
(0.6)\end{array}$ \\
\hline $\begin{array}{l}\text { Density (thousands of } \\
\text { persons } / \mathrm{km}^{2} \text { ) }\end{array}$ & & & $\begin{array}{l}-0.14 \\
(0.1)\end{array}$ & & & $\begin{array}{l}0.82 \\
(0.1)\end{array}$ \\
\hline $\begin{array}{l}\text { Urbanization ( } \% \text { pop. in } \\
\text { cities over } 100,000)\end{array}$ & & & $\begin{array}{l}-0.02 \\
(0.6)\end{array}$ & & & $\begin{array}{l}-0.5 \\
(0.6)\end{array}$ \\
\hline Constant & $\begin{array}{l}5.68 \\
(4.5)\end{array}$ & $\begin{array}{l}-23.12 \\
(3.1)\end{array}$ & $\begin{aligned}-15.56 \\
(1.7)\end{aligned}$ & $\begin{array}{l}-4.86 \\
(0.9)\end{array}$ & $\begin{array}{r}-23.73 \\
(2.2)\end{array}$ & $\begin{array}{r}-14.04 \\
(0.1)\end{array}$ \\
\hline $\mathrm{R}^{2}$ & .14 & .34 & .37 & .23 & .32 & .35 \\
\hline Degrees of freedom & 54 & 53 & 50 & 35 & 34 & 31 \\
\hline F-ratio*t & 3.0 & 2.2 & 2.4 & 2.7 & 1.3 & 1.5 \\
\hline
\end{tabular}

*t-ratios for the hypothesis that each coefficient is insignificant are shown in parentheses. For a one tailed test $t_{10} \approx 1.3, t_{.05} \approx 1.7$; for a two tailed test $t .10 \simeq 1.7$, t.05 $\simeq 2.0$.

**Each F-ratio presented is for the hypothesis that the measures of heterogeneity are jointly insignificant. For the 6 columns of the table $F_{.10} \simeq 2.1 ; F_{.05}=2.7$.

the smaller sample of 40 nations, where a measure of economic heterogeneity is also available, the table presents similar regression estimates. The table also reports the $t$-ratio for each estimated coefficient.

As Table 2 indicates, the indices of religious, ethnic and linguistic heterogeneity retain the same sign and similar magnitudes in all six regressions. In the first three regressions, the coefficients of these indices are each significantly different from zero at greater than the .10 level. In regression (4), when the income inequality measure is added and the size of the sample is reduced to 40 observations, the measures of heterogeneity remain significant when taken as a group. Even with this reduced sample, however, the measure of income inequality is highly significant. Finally, in 
regressions (5) and (6), with the other variables added, we can no longer clearly establish that the heterogeneity measures are significant. These simple regressions explain between 14 and 37 percent of the variance in homicide rates across the different samples.

As noted in Table 1, the measures of ethnic and linguistic heterogeneity are highly correlated in both samples. One implication of this collinearity is that it is difficult, statistically speaking, to estimate the separate effects of these two influences upon homicide rates. The coefficients reported in Table 2 are of course unbiased, but imprecise. For this reason, the $F$-ratio for the set of heterogeneity measures is reported for each specification of the model. The $F$-ratio tests the hypothesis that the heterogeneity measures as a group are significantly different from zero, regardless of the correlations among them. For the larger sample of countries, the hypothesis that heterogeneity is not associated with increased homicide is rejected at the .10 level or greater. When the size of the sample is reduced to 40 countries and the Gini coefficient is added (equation 4), heterogeneity of population is still significantly related to homicide.

Multiplicative (semi $\log$ and double $\log$ ) specifications of the relationship (not shown) yielded the same qualitative results. The coefficients of the heterogeneity measures were stable across alternative specifications, and the pattern of statistical results was similar.

As an illustration of the effect of heterogeneity upon homicide, Table 3 compares the homicide rate of the United States with the rates found in two other industrialized democracies, Sweden and Japan, that are conspicuously more homogeneous in terms of language, religion, and ethnicity. It also presents the differences in rates for these countries that are predicted from the data in our sample using the coefficients from regression (4) in Table 2. As the table indicates, the homicide rate in the United States exceeds the rate in Japan (Sweden) by about 6.7 (7.1) homicides per hundred thousand. In part, these observed differences in homicide rates are attributable to the substantial differences in religious, ethnic,

Table 3. COMPARISON OF ACTUAL AND PREDICTED DIFFERENCES IN HOMICIDE RATES FOR THREE COUNTRIES

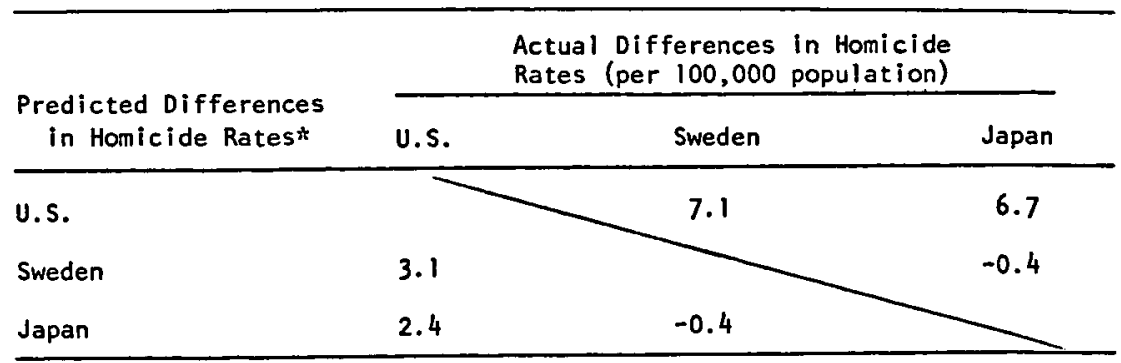

*Predictions derived from Table 2, regression (4). 
linguistic, and economic heterogeneity among these countries. For example, increased heterogeneity of the U.S. population relative to Japan is associated with a predicted difference in homicide rate of 2.4 per hundred thousand. Heterogeneity accounts for about 35 percent of the difference in the homicide rates between Japan and the United States, and more than 40 percent of the difference in homicide rates between Sweden and the United States.

\section{Interpretations}

The foregoing results suggest that, while differences among nations in homicide rates can by no means be attributed entirely to differences in population heterogeneity, nevertheless there is a significant, if complex, relationship between homicide rates and measures of heterogeneity.

These results cannot, of course, be considered a test of any particular theoretical model. We have not presented a well-formulated theory linking homicide to population heterogeneity, much less specific postulates from which the functional forms for the regression estimates are derived. Nevertheless it is possible to theorize about the causal factors underlying these results.

\section{CULTURE CONFLICT}

One striking result, consistent across all estimated regressions, is that homicide rates are positively related to ethnic heterogeneity but negatively related to linguistic (and, to a lesser degree, religious) heterogeneity. This might seem puzzling, since the population subgroupings that underlie both of these indices are roughly similar. Indeed, as we have noted, the measures of these two aspects of population heterogeneity are highly correlated in both of our samples. Thus, on empirical grounds, these indices might well be assumed to measure a single construct-ethnolinguistic fractionalization. Apart from statistical reasons, then, why should the indices have different signs in multiple regressions?

There is a plausible theoretical interpretation, consistent with the conflict-of-cultures theory of deviance discussed at the beginning. When cultural and/or ethnic groups within a nation's population have different languages, contact between members of those groups is less likely. Thus the cultural experience of a typical member of one of these groups will be more homogeneous. Only when members of different ethnic groups share a common language are they likely to have much intercourse, and only then is there likely to be much exposure to norms, sanctions, and patterns of authority that differ from, and hence might tend to weaken the hold of, those of one's own group. Consequently, if such mutual erosion of conflict- 
ing cultures is important in affecting rates of homicide, we should not be surprised to find that ethnic and linguistic heterogeneity have opposite signs when both variables are accounted for simultaneously.

A similar explanation may underlie the negative effect attributed to religious heterogeneity. Members of different religious groups tend to live apart, attend different schools, and so forth; holding constant the level of ethnic diversity, the higher the level of religious diversity the lower the level of intergroup contact. One would expect that this isolating effect would be less marked, however, for religious differences than for linguistic differences, and in fact our results show a stronger negative relationship between homicide and linguistic diversity than between homicide and religious diversity. ${ }^{9}$

\section{DISPLACED AGGRESSION}

Arguably these results are, by somewhat similar logic, also consistent with a displaced aggression theory of homicide. Thus, it might be that the degree of (displaced) aggression that an individual feels toward members of a different group (but which he takes out on members of his own group) is directly related to the degree of contact that he has with that other group, and that such contact is reduced if the other group has a different language or religion from his own. This interpretation seems somewhat less persuasive than the culture conflict interpretation suggested above, however, since casual observation suggests that linguistic and, especially, religious distinctions are among the types of inter-group differences that lead most strongly to inter-group hostility (and thus, presumably, by extension to displaced aggression that is intra-group).

\section{A DURKHEIMLAN INTERPRETATION}

A rather different, Durkheimian interpretation is also available. In Suicide, Durkheim speculates briefly on the social factors that are conducive to homicide. He suggests that homicide is likely to be most common where social regulation (the extent to which collective morals and authority effectively constrain the means used by individuals to achieve their personal goals) is weak. While Durkheim does not address the point directly, it could be argued, consistently with the discussion of culture conflict above, that ethnic diversity does lead to a breakdown in the social consensus supporting collective authority. Different groups will have differing norms and, perhaps more importantly, differing ideas about such institutions as marriage, the family, schools, and the criminal justice system, appropriate for imposing and enforcing those norms.

But Durkheim also suggests that high rates of homicide are likely to correspond to a high degree of social integration (the extent to which 
collective consciousness dominates individual consciousness, i.e., the extent to which peoples' desires and beliefs are given to them by the group to which they belong instead of being largely personal in origin, or individuated). A high level of integration fosters low respect for the value of any single individual and his interests, and simultaneously leads to strong social passions. "[N]o soil is so favorable to the development of the specifically homicidal passions," Durkheim argues (356), and he notes in this connection that intensity of religious faith can be an important element of integration. Thus one could argue-though Durkheim himself does notthat religious heterogeneity within a given society tends to break down such religious integration, and hence acts as a deterrent to homicide. ${ }^{10}$ Linguistic diversity could have a similar effect, for when subgroups cannot communicate, development of a "collective consciousness" will necessarily be impeded.

We do not wish to suggest that we find this rationalization particularly compelling, nor do we wish to impute undue clarity or coherence to Durkheim's conceptual scheme. Rather, we wish simply to emphasize that, even if we confine ourselves to the existing literature, alternative theories are consistent with our results. ${ }^{11}$

\section{INCOME}

The positive correlation between income inequality and homicide is consistent with the conventional belief that economic frustration and relative poverty tend to breed crime. The inverse relationship between homicide and per capita GNP suggests that absolute poverty is also conducive to crime. 12

\section{URBANIZATION}

The relationship between urbanization and crime has been the subject of an extensive literature (see Archer and Gartner for a survey). Empirical studies have shown that the homicide rate for large cities within any given country generally exceeds the homicide rate for the country as a whole, and that the homicide rate for large cities generally exceeds the rate for smaller cities within the same country (e.g., Archer and Gartner). ${ }^{13}$ One might be tempted to infer from these studies that, in general, the more urbanized a country is, the higher will be its homicide rate. Yet our results-which show no significant relationship, once other variables are controlled for-suggest otherwise. ${ }^{14}$

However, our results do not necessarily conflict with the earlier studies; several theories are consistent with both sets of findings. For example, the conditions of city life may have no causal influence on homicide; instead, an unusual proportion of a society's homicides may simply 
take place in cities, perhaps because cities tend to attract those who are most likely to be homicidal. Alternatively, even if city life is conducive to higher rates of homicide, other changes in society associated with the developmental process that gives rise to urbanization may tend to lower a society's overall homicide rate, cancelling out any effects of city growth per se.

\section{AGE STRUCTURE}

The strong positive correlation between homicide rates and the percentage of the population between 15 and 25 years of age is consistent with figures for the U.S. showing that homicide, like most other crime, is committed disproportionately by the young (Wolfgang, b). Indeed, these results suggest that differences in age structure account for more of the variation among countries in homicide rates than the three social heterogeneity measures (ethnicity, language, and religion) combined. ${ }^{15}$

\section{NEW SOCIETIES}

If, for any of the regressions reported above, we allow the constant term to vary according to whether a nation is in the Western Hemisphere, we find that the constant term is significantly larger for the Western Hemisphere nations. It is tempting to attribute at least part of this unexplained difference between homicide rates in the Western Hemisphere and those in the rest of the world to a frontier effect. All of the Western Hemisphere nations, after all, are relatively young societies, and all have been heavily populated by immigrants who may well have been unusually independent, aggressive, and materialistic, and who had to struggle to make their way in the new land. But such an argument, at least on its face, is not consistent with the markedly low rates of homicide to be found in Canada, Australia, and New Zealand.

\section{Conclusions}

One must necessarily be wary in drawing causal inferences from crosssectional studies, since such studies may fail to control for crucial factors. Nevertheless, the results presented here provide some support for theories suggesting that population heterogeneity is a significant causal factor in homicide. On the other hand, these results suggest that the relationship between homicide and heterogeneity is complex. It is evidently a mistake to think of population heterogeneity as a unidimensional variable that has a consistently positive correlation with homicide. Rather, when several dimensions of heterogeneity are considered jointly, we find that some 
forms of heterogeneity seem conducive to homicide, while others work against it. The significant underlying factor is evidently the degree of actual interaction between differing cultural or ethnic groups. More closely focused studies will be necessary to confirm this interpretation.

The results also provide evidence concerning other factors that might influence crime rates. A low level of income per capita and a high proportion of young people in the population are associated with high levels of homicide, while urbanization and population density seem to have no important effect.

\section{Notes}

1. A casual comment appearing in an article in the New York Times Magazine provides a good example: "[The State of] Washington, with a relatively homogeneous population, has a low crime rate, and Seattle is considered one of the nation's safest cities" (Nordheimer, 112).

2. A stylized example may clarify this notion. Suppose that two boys from different families live in the same neighborhood. The family of one of the boys belongs to a cultural group in which, so far as children are concerned, mothers are the primary source of moral authority and discipline, while grandfathers are conventionally pleasant figures whose primary role is to be indulgent and generous toward their grandchildren. The family of the other boy belongs to a different group in which, in contrast, mothers are assigned a weak and subordinate role and grandfathers serve as the ultimate source of moral authority within the family. Prolonged association between the boys might lead the first boy to discover that mothers are not universally respected and obeyed, and thus to lose some of his respect for the authority of his own mother, while the second boy might undergo a similar change of attitude toward his grandfather. The resulting damage to the authority systems in the two families might lead both boys to become less disciplined in general.

3. Sellin also suggests that culturally heterogeneous societies may experience high crime rates because the norms of the dominant group(s), which form the basis for the criminal law, proscribe activity that is deemed permissible or even laudatory by the norms of other groups in the society. Sellin's discussion of culture conflict as a cause of crime does not always distinguish clearly between this theory and that which is outlined in the text.

4. A similar theory also seems to lie at the core of Lord Devlin's reasoning in his contribution to the classic jurisprudential debate on the legal enforcement of morals.

5 . Not all theorists, it should be noted, are convinced that there is a direct link of any sort between population heterogeneity and crime. For example, the subculture of violence view of criminal behavior suggests that no simple relationship of this type should be expected (Wolfgang and Ferracuti).

6. As discussed below, our analysis is based on two samples of data: one containing observations on 58 nations; and another containing observations on 40 nations. Details about the specific definitions and sources of these data, as well as copies of the data sets, may be obtained from the authors on request.

7. Other measures of diversity or heterogeneity have been proposed and widely used by sociologists. Indeed, an alternative measure of heterogeneity, $A$, where

$A=1-\sum_{i=1}^{N} p_{i}^{2}$,

was proposed by Greenberg specifically to indicate linguistic diversity, was recommended by Lieberson for the measurement of religious heterogeneity, and was used by Webb to measure the division of labor (see also Bell; Goodman and Kruskal; Lieberson et al.). Another measure, the "dissimilarity index," has been widely used by sociologists to quantify residential segregation (Taeuber and Taeuber).

A much cruder index of heterogeneity (e.g., a dummy variable signifying that at least some arbitrary fraction of the population spoke a common lauguage) was employed by McDonald.

In contrast to all these arbitrary measures, the entropy index can be easily aggregated 
or disaggregated. Compare, for example, the discussion of Lieberson with Theil. Compare also the properties of the entropy index in the two-group case to the criticisms of dissimilarity indices raised by Cortese et al. and the subsequent discussion by Taeuber and Taeuber and Cohen et al.

8. For example, Basques, Catalans, and Galicians are all counted as separate ethnic groups within the population of Spain. This same subcategorization is then applied to all other countries with significant subpopulations of Spanish origin, such as France and the Latin American nations.

9. Note that our results suggest that McDonald's findings of no important relationship between heterogeneity and crime may be misleading. When, as in McDonald's study, only a single index of heterogeneity is entered into any given regression, the coefficient assigned to that index may be spuriously small and insignificant because the regression has attributed to the index the effects due to other forms of heterogeneity that are positively correlated with that index but that have an effect on crime rates that is opposite in direction to the effect actually caused by the form of heterogeneity represented by the index.

10. Indeed, at another point Durkheim suggests that, at least in some cases, religious faith becomes more intense when the religious group constitutes a minority within the nation.

11. Krohn uses cross-national data to test a rather differently formulated Durkheimian theory of crime, and finds that the results fail to confirm that theory.

12. These cross-section results contrast with Wolpin's longitudinal studies showing positive correlation between rates of violent crime and increases in GNP per capita for various developed countries.

13. In fact, Archer et al. find that, at least for the U.S., the positive correlation between city size and homicide rate holds only for cities in excess of roughly 10,000 population; below that level, city size appears to be inversely related to the homicide rate.

14. See also Krohn, reporting an ambiguous relationship between urbanization and crime, including homicide, in a cross-national study. Krohn's results in this respect are difficult to compare with ours because, among other things, he does not report tests of significance.

15. Forst, in a cross-section study of homicide using statewide observations from the United States, does not find a significant age effect, but his sample contains too little variation in age for this result to be very meaningful.

\section{References}

Allison, P. D. 1978. "Measures of Inequality." American Sociological Review 43:865-80. Angell, R. C. a:1951. "The Moral Integration of American Cities." American Journal of Sociology 57(1): Part 2.

b:1974. "The Moral Integration of American Cities: II." American Journal of Sociology 80:607-29.

Archer, D., and R. Gartner. 1976. "Violent Acts and Violent Times: A Comparative Approach to Post War Homicide Rates." American Sociological Review 41: 937-63.

Archer, D., R. Gartner, R. Akert, and T. Lockwood. 1978. "Cities and Homicide: A New Look at an Old Paradox." Comparative Studies in Sociology 1:73-95.

Bayley, D. H. 1976. "Learning About Crime-The Japanese Experience." The Public Interest : 55-68.

Becker, G. S. 1968. "An Economic Approach to Crime and Punishment." Joumal of Political Economy 76:169-209.

Bell, W. 1954. "A Probability Model for the Measurement of Ecological Segregation." Social Forces 32(May):357-64.

Blau, Peter. 1977. Inequality and Heterogeneity. New York: Free Press.

Bordua, D. J. 1958. "Juvenile Delinquency and 'Anomie': An Attempt at Replication." Social Problems 6:230-37.

Brown, Jerram L. 1975. The Evolution of Behavior. New York: Norton.

Buss, Arnold H. 1961. The Psychology of Aggression. New York: Wiley. 
Clinard, M. B., and D. J. Abbott. 1973. Crime in Developing Countries: A Comparative Approach. New York: Academic Press.

Cohen, J. K., R. F. Falk, and C. F. Cortese. 1976. "Reply to Taeuber and Taeuber." American Sociological Review 41:889-92.

Cortese, C. F., R. F. Falk, and J. K. Cohen. 1976. 'Further Considerations on the Methodological Analysis of Segregation Indices." American Sociological Review 41:630-37.

Devlin, Patrick. 1965. The Enforcement of Morals. Oxford: Oxford University Press.

Dollard, John, Leonard W. Boob, Neal E. Miller, O. H. Mowrer, and Robert R. Sears. 1939. Frustration and Aggression. New Haven: Yale University Press.

Durkheim, Emile. 1951. Suicide. Tr. John A. Spaulding and George Simpson. New York: Free Press, 1966.

Fenigstein, A., and A. H. Buss. 1974. "Association and Affect as Determinants of Displaced Aggression." Joumal of Research in Personality 7:306-13.

Ferdinand, T. 1967. "The Criminal Patterns of Boston Since 1849." American Joumal of Sociology 73:84-99.

Forst, Brian E. 1977. "The Deterrent Effect of Capital Punishment: A Cross-State Analysis of the 1960's." Minnesota Law Review 61:743-67.

Garfinkel, H. 1949. "Research Note in Inter- and Intra-racial Homicides." Social Forces 27(May):369-81.

Goodman, L. A., and W. H. Kruskal. 1959. "Measures of Association for CrossClassifications II: Further Discussion and References." Journal of the American Statistical Association 54:123-63.

Greenberg, J. H. 1956. "The Measurement of Linguistic Diversity." Language 32:123-63.

Hanushek, Eric A., and John E. Jackson. 1977. Statistical Methods for Social Scientists. New York: Academic Press.

Hart, H. L. A. 1963. Law, Liberty and Morality. Stanford: Stanford University Press.

Hindelang, J. J. 1974. "The Uniform Crime Reports Revisited." Joumal of Criminal Justice 2:370-81.

Holmes, D. S. 1972. "Aggression, Displacement and Guilt." Journal of Personality and Social Psychology 21:296-301.

Konecni, V. J., and A. N. Doob. 1972. "Catharsis Through Displacement of Aggression." Journal of Personality and Social Psychology 23:279-87.

Krohn, M. D. 1978. "A Durkheimian Analysis of International Crime Rates." Social Forces 57(December):654-70.

Lander, Bernard. 1954. Towards an Understanding of Juvenile Delinquency. New York: Columbia University Press.

Lieberson, S. 1969. "Measuring Population Diversity." American Sociological Review 43:850-62.

Lieberson, S., G. Dalto, and M. E. Johnston. 1975. "The Course of Mother-Tongue Diversity in Nations." American Journal of Sociology 81:34-62.

McDonald, Lynn. 1976. The Sociology of Law and Order. Boulder: Westview Press.

Muller, Siegfried H. 1964. The World's Living Languages. New York: Ungar.

Mulvihill, D. J., and M. M. Tumin. 1969. Crimes of Violence. Vols. 11, 12, 13. Washington: GPO.

Nordheimer, J. 1978. "All-American Boy on Trial." The New York Times Magazine (December 10):46 et seq.

Porterfield, Austin L. a:1948. "A Decade of Serious Crimes in the United States: Some Trends and Hypotheses." American Sociological Review 13:44-54. b:1965. Cultures of Violence. Fort Worth: Leo Polishman Foundation. 
Sellin, Thorsten. 1938. Culture Conflict and Crime. New York: Social Science Research Council.

Taeuber, Karl E., and Alma F. Taeuber. a:1965. Negroes in Cities. Chicago: Aldine Publishing Company.

b:1976. "A Practitioner's Perspective on the Index of Dissimilarity." American Sociological Review 41:884-89.; Taylor, Charles L., and Michael C. Hudson. 1971. Cross-National Aggregate Data for World Handbook of Political and Social Indicators [MRDF]. Ann Arbor: Center for Political Studies, University of Michigan [producer]. Ann Arbor: Inter-University Consortium for Political and Social Research [distributor].

Theil, Henri. 1972. Statistical Decomposition Analysis. Amsterdam: North Holland.

Webb, S. D. 1972. "Crime and the Division of Labor: Testing a Durkheimian Model." American Joumal of Sociology 78:643-56.

Wolfgang, M. a:1967. "Criminal Homicide and the Subculture of Violence." In Marvin Wolfgang (ed.), Studies in Homicide. New York: Harper \& Row. b:1967. "A Sociological Analysis of Criminal Homicide." In Marvin Wolfgang (ed.), Studies in Homicide. New York: Harper \& Row.

Wolfgang, Marvin, and Franco Ferracuti. 1967. The Subculture of Violence. London: Tavistock.

Wolpin, K. I. 1978. "A Time Series-Cross-Section Analysis of International Variation in Crime and Punishment." Yale University, unpublished manuscript. 